\title{
BOCETO PARA UN ESTUDIO DEL MUNICIPIO ESPAÑOL EN INDIAS
}

Fis

NTRE las instituciones civiles y políticas que el Imperio español trasplantó a las tierras de Indias, pocas superan en transcendencia histórica al Municipio por lo que éste significó como elemento civilizador y social y por la influencia que ejerció en la sociedad criolla, sobre todo al llegar el momento de la emancipación y, más tarde, en la formación de los Estados que de ellas se desprendieron.

$\mathrm{Su}$ estudio es una de las grandes tareas apenas iniciadas, y creo que ocuparse de él entre estos dos movimientos, hispanista y municipalista, que se inician en la nueva España tiene un innegable interés. Como decía el grande historiador de las instituciones lusitanas Alejandro Herculano, "el estudio del Municipio en sus orígenes y en sus modificaciones como elemento político debe tener para la generación actual un alto valor histórico, ahora que la experiencia viene demostrando la necesidad de restaurar ese olvidado pero indispensable elemento de toda buena organización social".

\section{Características de la obra española de América.}

Al investigar en la obra realizada por los españoles en América, salta a la vista un hecho que diferencia nuestro gran esfuerzo imperial del realizado por los demás países colonizadores. $Y$ es que las empresas hispanas en los territorios de Ultramar son ompresas de Estado, no de particulares ni de compañías mercantiles o de sectas religiosas o políticas, como ocurre en el caso de Inglaterra, de Holanda y de Francia.

El pueblo español, organizado por su Monarquía perfecta, descubre y ocupa tierras desconocidas que quedan sujetas a la Corona. y a las cuales se traslada la soberanía española con sus órganos legales y sus instituciones típicas, hasta el punto de que los Colón, los Cortés y los Pizarro obran en nombre y dentro del orden superior del Es- 
tado, y aun así, rápidamente, a los descubridores y conquistadores geniales suceden los que podríamos llamar altos burócratas, como La Gasca y Mendoza, que realizan la plena incorporación jurídica y dan estructura a la española a las tierras y a los pueblos indianos.

La grosera deformación de las realidades históricas llevada a cabo por los historiadores liberales y románticos (y antihispánicos, por lo tanto) de los siglos XVIII y XIX nos quiso presentar este celo del Estado como una opresión de la tiranía real sobre el genio de hombres insignes como los citados. Nada más falso ni más burdo que esa interpretación desdichada. La nación, el pueblo (usando terminología moderna) representados por sus únicos órganos legítimos y legales: el Rey y sus Consejos, fué la que realizó la ingente tarea de incorporar las Indias a la vida de Occidente. $Y$ esa tarea y su responsabilidad histórica ni fué ni debía ser entregada en feudo vitalicio o hereditario a ningún particular, por excelsos que fueran sus servicios.

Realmente, el primer documento político-jurídico que hay en la legislación de Indias, después de las capitulaciones de Santa Fe, es el que contiene las instrucciones que el Rey y la Reina dieron a Cristóbal Colón cuando éste, tras el descubrimiento, realizó su segundo viaje. Dicho documento va fechado en Barcelona el 23 de mayo de 1493 y es de una importancia capitalísima, pues constituye la base y el arranque de toda la obra hispánica en el nuevo mundo. En él queda bien claramente sentada la soberanía pura y directa de la Monarquía. Después de abìir la "Instrucción" con un artículo primero que dispone la conversión amorosa de los indios a la fe y el envio para realizarla de fray Buil y otros religiosos, se dice en el artículo 10: "El Almirante, do poblare, nombrará alcaldes y alguaciles que administren justicia y oigan las apelaciones, o primeras instancias, como más viere que cumplen." En el 12: "En cualquier justicia dirá el pregón que la manda hacer el Rey e la Reina". Y en el 13: "Toda provisión se despachará bajo el nombre de don Fernando y doña Isabel..., firmado de Colón, antes de Escribano; selladas con el se!lo real."

No ocurre, por lo tanto, lo que en Angloamérica, donde un grupo de comerciantes o de proscriptos establecen factorías que son base de colonias de explotación ajenas a la soberanía directa y a las preocupaciones espirituales de los gobernantes metropolitanos.

Quede, pues, bien clara esta afirmación. Las Indias fueron provincias de la Corona de Castilla, consideradas ellas y sus habitantes en completo pie de igualdad a la Península y a los peninsulares. El 
concepto jurídico-económico de colonia no existió en el Imperio español. Las leyes de Indias responden a los mismos principios que las de Castilla, superándolas en propósitos humanos y evangelizadores. Conocida es, en este aspecto, la Real Cédula de Felipe II en la cual se establece que, "siendo de una Corona los Reinos de Castilla y los de Indias, las leyes y orden del Gobierno de los unos y de los otros deben ser los más semejantes y conformes que ser puedan. Los de nuestro Consejo, en las leyes y establecimientos que para aquelios Estados ordenaren, procuren reducir la forma y manera de gobierno en ellas al estilo y orden con que son regidos y gobernados los reinos de Castilla y León, en cuanto hubiera lugar y permitiese la diversidad y diferencia de tierras y naciones." El Derecho positivo de Castilla fué Derecho supletorio en las Indias, siguiendo el orden de prelación que para aquél se señala en las leyes de Toro.

\section{La tradición municipalista en Castilla.}

Los grupos de emigrantes que van llegando a las Indias, !levados por los impulsos aventureros de la raza, por la vocación misional de la fe y por el interés de lucro que despierta la riqueza de aquellos países, establecen campamentos y poblados en los que son necesarias autoridades y a los que es necesario dotar de un orden jurídico. Lógico es que esas autoridades y ese orden respondan a las tradiciones de Castilla, de donde provienen los pobladores. $\mathrm{Y}$ así surgen los primeros Municipios españoles en Indias.

En la repoblación y organización de ciudades tenía Castilla tradiciones gloriosas y fecundas, como que en toda su historia medieval existe el principalísimo suceso de la Reconquista y con ella el problema político-jurídico de asentar a los nuevos pobladores. De ahí la existencia de nuestras interesantísimas Cartas otorgadas y Fueros de frontera, que la historia del Derecho español registra desde el siglo $\mathrm{X}$.

Mas estos Fueros municipales del medievo se caracterizan-como fruto de su época y de las circunstancias especiales de España-por la existencia del privilegio con que se paga la lealtad y las aportaciones de las ciudades y villas de la retaguardia, o se facilita, mediante exención de tributos, concesión de campos laborables, etc., la repoblación de los lugares peligrosos lindantes con el moro y abiertos a las desoladoras correrías de la guerra de algaradas.

El espíritu, cuando no la letra, del Fuero Juzgo, el magno "Liber judiciorum", traducido y adaptado a la realidad castellara con una mezcla romano-germana-canónica, es el que informa los Fueros mu- 
nicipales, que tiene un carácter aislado para proyectarse sobre ciudades o castas, como, por ejemplo, en el caso de Alfonso VI, que, tras ocupar 'Toledo, concede a la ciudad tres Fueros distintos: uno a lcs pobladores castellanos, otro a los residentes mozárabes y otro a la soldadesca franca que le ayudó. Este caso se repite en nuestros siglos medios y contribuye a la anarquía administrativa y judicial de Castilla, a la que se intenta repetidamente poner remedio por Reyes $\mathbf{y}$ Cortes desde el Fuero Real de Alfonso el Sabio.

Teniendo en cuenta estos antecedentes, era muy de temer que algo parecido-salvando, claro está, las distancias de tiempo y cspacio-ocurriese en las Indias, donde se enlazaba la Cruzada contra el moro con la obra misionera y conquistadora sobre los bárbaros paganos del Nuevo Mundo. Ambas empresas estaban alentadas por idéntico espíritu y unidas con solución de continuidad de acción, ya que las mismas cruces y las espadas de Granada son las que prosiguen su gesta sublime más allá de la mar oceana.

Pero los pueblos caminan inexorablemente por la calzada de la Historia y nunca vuelven sus pasos para atrás. Entre el Estade y las concepciones de los siglos XI, XII y XIII y las del XVI median abismos. La España unificada y en plenitud, robusta en sus órganos de poder de la centuria décimosexta, tenía que obrar, y lógicamente obró, de muy distinta manera que la España dividida y enfeudada de los Reyes caudillos, los nobles turbulentos y las ciudades engreídas. De ahí que la organización municipal americana, aunque respondiese al tipo medieval de la de Castilla, fuese más regular que ésta y más obediente a los mismos principios, en severa dependencia de la autoridad superior del Estado.

\section{Los Cabildos indianos.}

¿Cómo y cuándo aparecen los primeros Cabildos indianos? La Recopilación de las Leyes de Indias se ocupa de la fundación y crganización de las poblaciones en su libro IV. Fuera de la magna Recopilación, en cédulas y leyes recogidas, en gran parte, en el poco cc:nocido Cedulario índico de José Manuel de Ayala, hay numerosísimas disposiciones relativas a la materia municipalista y al persistente esfuerzo y preocupaciones del Gobierno español por la vida municipal en las provincias ultramarinas.

En el citado título IV de la "Recopilación de las leyes de los Reinos de Indias", de 1680 , se dispone y prevé con maravillosa capacidad, que colma nuestro asombro, cómo se han de elegir los lugares para edificar las ciudades, buscándose ventajas estratégicas y sani- 
tarias; cómo ha de llevarse la fábrica del caserío y el trazado de jas calles y plazas y de qué manera ha de gobernarse al vecindario y por quiénes. Se establecen distintos tipos de poblaciones, las cuales podrían ser ciudades, y éstas, a su vez, metropolitanas o sufragáneas, y villas y lugares. Para el gobierno de unás y de otras se señalan dignidades y manera de elegirlas. Las metropolitanas contarán con un juez adelantado o alcalde mayor o corregidor o alcalde ordinario, doce regidores, dos o tres oficiales de la Hacienda real, dos fieles ejecutores y dos jurados de cada parroquia, un procurador general, un mayordomo, un escribano de Concejo, dos escribanos públicos, otro de Minas y Registros, un pregonero mayor, un corredor de lonja y dos porteros. Las ciudades sufragáneas sólo contarían con ocho regidores y las villas con cuatro.

Claro está que esta letra legal no se cumplió en la práctica cün rigorismo; incluso el número de alcaldes y regidores fué objeto de diversas disposiciones. Mas este aspecto de detalle no tiene mayor intérés para la vida de la institución.

Se duelen algunos tratadistas contemporáneos de la frecuencia con que, a partir de los últimos años del siglo XVI, se incurrió en la venta de dignidades concejiles. Pero esa venta, inadmisible para los hombres de hoy, era práctica frecuente en la Europa de aquel tiempo, sobre todo en los momentos difíciles para la Hacienda del Estado, y no debía dar tan mal resultado en la Administración, ya que en pleno siglo XVIII uno de los autores más eminentes de la Historia, verdadero precursor de la Revolución liberal-me refiero a Montesquieu-, la defendió en el capítulo XX de su celebérrimo "Espíritu de las Leyes".

\section{El ejemplo de los Municipios cubanos.}

Desde luego, en la segunda década del siglo XVI ya funcionaban en América Municipios de tipo castellano. A la isla de Cuba le cabe la primacía en el desarrollo de los primeros Cabildos municipales. El gobernador Diego de Velázquez realizó diversas fundaciones de esta índole. $\mathrm{Y}$ es en Cuba donde la vida municipal adquiere en ese siglo mayor desarrollo y más alto interés histórico-jurídico, por referirse a sus Cabildos el más valioso documento municipalista de España en las Indias. Me refiero a las Ordenanzas de Alonso Cáceres, cuya importancia y transcendencia las hace merecedoras de una breve relación.

Alonso de Cáceres era un oidor de la Audiencia de Santo Domingo a principios del último tercio del quinientos. Como tal, y para dar. 
cumplimiento a la sabia disposición real que ordenaba visitas inspectoras a las poblaciones de su jurisdicción, fué Cáceres a Cuba, donde la vida municipal se desarrollaba en un ambiente de turbulencias y abandono. Cáceres, cumpliendo otra sabia disposición que disponía que por las Audiencias se redactasen ordenazas para las ciudades o villas que no las tuviesen, escribió en La Habana, el año de 1574, unas para aquella ciudad y la de Santiago de Cuba y demás Municipios de la isla.

"En estas Ordenanzas-dice el erudito escritor y académico don Jerónimo Bécker, en su obra "La política española en las Indias"se consigna el principio de la inviolabilidad del domicilio, prohibiendo que se entre en ninguna casa sin mandamiento del juez (artículo 18) ; se encomienda a la elección popular directa el nombramiento de un procurador, síndico, cuya asistencia al Cabildo era obligatoria "para ver lo que en los ordinarios se provee y poder contradecir lo perjudicial al pueblo o bien público, apelar y seguir la causa en nombre de la villa" (art. 20); se consagra en cierto modo el referéndum al prevenir al procurador del pueblo que, ante cualquier asunto grave, lo consulte con los vecinos, convocándolos a este fin (art. 21), y se previene que las crueldades con los esclavos serán castigadas no sólo compendiendo al amo a que lo venda, sino escarmentándolo "conforme el exceso" (art. 61). Claro es que Cáceres no podía sustraerse por completo al espíritu centralizador de su época, y por Ello hubo de requerir en los Cabildos la presencia del Gobernador o, en su defecto, los alcaldes, haciendo a aquél juez de cuarto los regidores acordasen (arts. $2:^{\circ}$ y $4 .^{\circ}$ ) ; pero, al propio tiempo, consagró uno de los principales aspectos de la autonomía municipal al afirmar el derecho de los Ayuntamientos de reunirse en sesión extraordinaria por la sola convocatoria de sus alcaldes" (art. 5.9).

Con la admirable obra de Cáceres ocurrió algo, por desgracia frecuente, en la Administración española, tanto de la Península como de América. El Imperio, al lado de sus aciertos y de su magnífica y complicada concepción romana, adolecía del defecto de la lentitüd y del exceso de papeleo. Las Ordenanzas de Cáceres, terminadas en 1574, no fueron aprobadas hasta 1641, es decir, que entre trámites, informes y andanzas burocráticas en la Audiencia de Santo Domingo, primero, y en el Consejo de Indias, después, en păsar el mar en busca de aprobación y repasarlo, sancionadas ya, transcurrieron sesenta y ocho años; es decir, cerca de tres cuartos de siglo y más de la vida media del hombre.

La transcendencia y la importancia práctica y doctrinal de estas 
Ordenanzas constituye uno de los valores más puros y auténticos de la obra legislativa de España. La voz excelsa de Vázquez de Mella al referirse al Municipio indiano, en una de sus síntesis grandilocuentes, no encontró mejor elogio que calificarlo así: “...aquel Municipio glorioso de las Ordenanzas seculares de Alonso de Cáceres, que sirvieron, en el siglo XVIII, de base al de los Estados Unidos."

Según el ilustre tratadista cubano Jacobo de la Pezuela, en su notable "Ensayo histórico de la isla de Cuba", las Ordenanzas del oidor Cáceres constituyen "un monumento legislativo muy superior a la época en que se producía y dió forma a múltiples resoluciones dispersas, ofreciendo los Ayuntamientos cubanos no sólo una organización política perfectamente adecuada entonces a las funciones de su ramo, sino, además, base cierta de criterio en el desenvolvimierito de su actividad..." "No es fuera del caso observar-añade-que entre las reformas liberales a que aspiran los Municipios norteamericanos, contra la dura centralización legislativa que allí existe, una de ellas es ese veto municipal contra la legislatura del Estado, del que tenemos en las Ordenanzas de Cáceres un notable precedente entre las municipalidades cubanas y tan remoto como de mediados del siglo XVI."

El Municipio cubano, organizado sobre las bases que le dió Cárdenas, subsistió hasta bien entrado el siglo XIX, demostrando cun tan larga duración sus perfecciones, su humanidad, su justicia, su larga visión histórica y su utilidad práctica, es decir, la posesión de auténticos valores jurídicos.

\section{Ejemplos de las preocupaciones municipalistas del Imperio.}

Pero no se vaya a creer que esto que ocurría en Cuba era una excepción gloriosa en América, no. La vida municipal discurría vigorosa $\mathrm{y}$ fecunda en todas las provincias indianas, donde virtudes y defectos peninsulares se habían reproducido. El régimen de "Cabildos abiertos", equivalentes a los conocidos "Concejos abiertos" del Reino de Lueón, fué frecuentísimo en las tierras nuevas, sobre todo en Buenos Aires, donde sus recuerdos alcanzaron en más de una ocasión rango de historia.

Entre las virtudes municipales, bien merece señalarse la eficacia con que se reglamentó y organizó la vida, trabajo, sanicad, etc., de los vecinos. De magníficas disposiciones sobre esos aspectos hay numerosas muestras en la Legislación indiana. Unicamente leyéndolas y releyéndolas puede uno darse cuenta hasta dónde llegaba la rec- 
tora preocupación del Imperio por el buen orden, la salud y la vida de sus súbditos.

En un plan de divulgación, creo que no está de más recordar aquí algunas de esas disposiciones, no incluídas en la Recopilación de 1680 y sacadas del Cedulario que Ayala preparó en tiempos de Carlos III, y que contienen extremos curiosos e interesantes que demuestran la buena organización de nuestra Administración local en aquellos tiempos. Por ejemplo:

"Que los regidores no sean regatones, ni tengan tiendas, ni vivan so pena de cien castellanos de oro de multa y perdimiento del oficio." (Carlos I. Madrid, 12 de septiembre de 1528.)

"Que los regidores no sean regatones, ni tengan tiendas, ni vivan en la casa del Gobernador." (La Reina. Ocaña, 27 de octubre de 1530.)

"Que se haga en Los Angeles la visita de mesones y ventas y que se pongan aranceles." (La Reina. Valladolid, 20 de julio de 1538.)

"Ordenanzas del Virrey de Méjico para evitar la matanza de cabras y ovejas, que hacen acaparadores en sitios ocultos." (Virrey don Luis de Velasco. Méjico, 26 de enero de 1611.)

"Que no se haga repartimiento de gallinas a los chinos a precios baratos y que no se tome el arroz de los tributos cobrados, sino después que se sepa qué sobra para las necesidades públicas." (Felipe III. 29 de mayo de 1630. Esta disposición ya dirigida a la Audiencia Real de la ciudad de Manila, de las islas Filipinas.)

"Se niega a Méjico que tenga un regidor para inspeccionar las carnicerías con salario, porque esta carga caería sobre los vecines en aumento del precio de la carne." (Carlos II. Madrid, 5 de julio de 1682.)

"Se regula el empleo de los baños temascales en Méjico, permitiendo los privados y limitando a doce el de los públicos: seis para hombres y seis para mujeres." (Carlos II. Madrid, 12 de diciembre de 1691.)

"Se previene tasa para el maíz, cazabe, semillas, legumbres..., que vendieren los seglares y los eclesiásticos en muelle, puente o en casa, y no para el maíz y cazabe que vendieran los labradores productores, que podrán venderlo libremente." (Carlos II. Madrid, 29 de junio de 1692.)

"Pidiendo informe al Virrey de Méjico acerca de una instancia de la ciudad de Veracruz en que se representan los inconvenientes de las aguas que emplean, por ser insalubres, y pide licencia para poner un arbitrio sobre la harina, a fin de llevar agua de otro lugar distante." (Felipe V. Madrid, 1 de febrero de 1723.) 
"Se aprueba la intervención del Virrey de Méjico en fijar el precio de los ganados entre ganaderos y carniceros, para asegurar el abastecimiento de carnes." (Felipe V. San Ildefonso, 19 de agosto de 1726.)

"Que el arrendador de abastos de carne de Méjico no lo sea por períodos mayores de cuatro años." (Felipe V. San Ildefonso, 5 de agosto de 1734.)

"Que se cierren las tiendas y pulperías de la Concepción de Chile temprano por la noche y se recojan también pronto las vendedoras del portal para evitar escándalos." (Fernando VI. Madrid, 5 de septiembre de 1794.)

"Haciendo general el arbitrio de veinte reales por cada mula que entra con carga de aguardiente, al igual que se aprobó para Lima, destinándose dicho arbitrio al arreglo y limpieza de las calles." (Carlos III. El Pardo, 24 de febrero de 1773.)

"Que se hagan planos de las ciudades de Nueva España y se envíen al Consejo de Indias." (Felipe III. Madrid, 22 de noviembre de 1621.)

"Que se envíe al Consejo de Indias censo de la población y listà de las ciudades y villas de Nueva España." (Carlos II. Buen Retiro, 21 de abril de 1679, y Madrid, 5 de agosto de 1681.)

La transcripción de los motivos, algunos de ellos nimios y encantadores, de muchas leyes municipales del Imperio, prueban más que un elocuente razonamiento, el desvelo con que nuestros gobernantes se ocupaban de los problemas municipales. Es realmente asornbroso. A miles de leguas de distancia, a través de mares, selvas, cordilleras, llanuras y páramos, entre las preocupaciones politicas y cortesanas de un Imperio combatido por poderosos y plurales enemigos que ya empezaban a babear las asquerosas difamaciones de la "leyenda negra", los católicos Reyes de las Españas y el Supremo Consejo de las Indias velaban con paternal interés por los más pequeños detalles de la vida municipal americana. Con el mismo anhelo que la madre escribe a su hijo ausente en lejania peligrosa sus santos consejos, ilustrados por mil pequeños matices, así el Estado español velaba y regía la sana y honesta existencia de sus súbditos blancos, mestizos y criollos de allá de la mar.

Una autonomía, que en su desarrollo práctico llegó muchas veces a ser exagerada por sus beneficiarios, caracterizó ciertos tiempos y ciertos cabildos. El espíritu arisco y orgulloso de las gentes trasladalas a Ultramar convirtió en franco abuso lo que debió haber sido prudente uso de una sana y natural independencia administrativa 
y hasta política, impuesta no sólo por las tradiciones peninsulares, sino también justificada por la distancia. Tales abusos llegaron, sobre todo en los primeros tiempos de la etapa civilizadora, a determinar verdaderos conatos de rebeldía, si no en armas, sí en postura jurídica. Y así, hasta hubo Ayuntamientos, como los mismos de Cuba antes de Alonso de Cáceres, que pretendieron vivir como pequeñas repúblicas que sólo acataban con un "cúmplase" las disposiciones de la Audiencia. Por fortuna, todo ello no pasó de un simple juego al que la unidad superior de la gran Monarquía-entonces en toda su gloriosa plenitud imperial-puso fin cuando a los territorios de Ultramar se les dió la espléndida organización y estructura que había de durar tres siglos.

\section{Los Municipios indigenas}

Otra curiosa manifestación del cristiano y humarísimo respeto que la Legislación española de Indias sentía por los indígenas y pur las tradiciones municipales está en la conservación y en la organización que dió a los poblados de indios puros, gobernados por sus alcaldes y regidores y conforme a sus costumbres, en tanto que éstas no se opusiesen al catolicismo. La finalidad de esta institución, que coincide con lo que en la terminología indiana se llaman "reducciones", era principal y doblemente, la robilísima de facilitar a los indios la cristianización y civilización, protegiéndolos y defendiéndolos al sustraerlos del dominio rapaz o del engaño de blancos y mestizos poco escrupulosos.

En esos poblados, para los que hay menciones abundantes en nuestra legislación indiana, sólo podían convivir con los indios el cura párroco adoctrinador y el legislador blanco $u$ oficial del Virrey, que representaba la autoridad y cobraba los tributos.

Este régimen, mitad de misión y mitad de Municipio, tan bien intencionado y $\tan$ perfecto en la teoría, fué ensombrecido muchas veces por el mismo defecto que pretendía evitar, y ello venía casi siempre de que el regidor blanco, al mismo tiempo que cobraba los tributos, era el encargado de vender y repartir los artículos de consumo y materias primas a los indios, con lo cual se daba pie para abusos y escándalos en los que, casi sin excepción, el cura tomaba el partido de los indígenas. "Alguno de estos empleados-dice el documentadísimo y españolísimo Mariano Torrentes en el "Discurso preliminar." de su justa y erudita "Historia de la Revolución Hispanoamericana"-adquirían antes riquezas inmensas por medio del re20 partimiento, o sea, de los préstamos de ganado, semillas, ropas y 
otros efectos, cuyo tráfico lo promovió la mịsma Corte de España con la idea de estimular al trabajo a aquellos pueblos perezosos, quienes, pudiendo granjearse fácilmente su precario sustento, holgaban la mayor parte del tiempo y se entregaban a una vida viciosa, inerte y deleitable; mas luego que S. M. tuvo conocimiento de los abusos que se cometían por este medio, tan plausible en su origen, fué suprimido dicho repartimiento."

La creación de los Intendentes, en tiempos de Carlos III, así como el envío de veedores y la saludable reacción que produjeron las informaciones de Jorge Juan y Antonio Ulloa, puede decirse que dieron fin a estos abusos. Es decir, que el mal de ese ensayo de Municipio indígena fué corregido por la acción superior y paternal de la Corona española.

\section{Detalles municipales.}

Volviendo a los Municipios de blancos y al desarrollo normal de su Administración y gobierno, al mismo tiempo que su lealtad al Rey y su colaboración a la obra civilizadora común, dice Navarro Lamarca en su notable Historia de América: "Los Ayuntamientos tenían atribuciones judiciales y administrativas. fijadas en la Ley o en sus privilegios originarios. Ejercían las judiciales los alcaldes, en primera instancia civil o criminal, y el Cabildo, en apelación, con sus asesores letrados. En lo administrativo, los Municipios eran teóricamente autónomos para todo lo concerniente a la policía y ornato de las ciudades, a la reglamentación de su vivir económico (tasas, ordenanzas de industria y comercio, etc.), inspección de cárceles, hospicios, etc., y a la moralidad e higiene públicas. En casos graves, los Cabildos convocaban, para mejor proveer, una especie de junta de asociados, formada por los notables o gentes de viso de la ciudad. Estas reuniones especiales tomaron el nombre de "Cabildos abiertos". En Buenos Aires, por ejemplo, hubo en el siglo XVII varios Cabildos abiertos para acordar donativos al Rey, resolver en urgencias de guerra e imponer a los indios castigos extraordinarios."

En la magna "Política indiana", del doctor Solórzano Pereyra, autoridad inapreciable y máximo tratado doctrinal de nuestro Derecho Indiano, se indica y especifica que "en las ciudades, villas y lugares de españoles que se iban fundando y poblando con suficiente número de vecinos se fuese jntroduciendo y disponiendo, al mismo paso, el Gobierno político, prudente y competente, que en ellas se requería y se creasen Cabildos, regidores y demás oficiales necesarios en tales 
repúblicas o poblaciones, los cuales, todos los años, sacasen y eligiesen de entre los mismos vecinos y ciudadanos sus jueces o alcaldes ordinarios, que, dentro de sus términos y territorios, tuviesen y exerciesen la jurisdicción civil y criminal ordinaria, no de otra suerte que si por el mismo Rey hubieran sido nombrados, que es el que dió a los Cabildos el derecho de estas elecciones y al modo y forma que se solía hacer y practicar en los Reinos de España."

De la seriedad y solemnidad con que se verificaban tales elecciones nos deja el mismo Solórzano Pereyra curioso testimonio al enseñarnos, por las Cédulas Reales de Lerma, que "por la gran distancia de su Rey y por el peligro de la tardanza, pueden sus moradores por derecho natural elegir estos magistrados o alcaldes ordinarios, que así los goviernen y juzguen siempre que sucediere morir o faltar por otra qualquiera causa o impedimento, el Governador, el Rey les huviese enbiado. Lo cual se practica así quando acontece, y los alcaldes ordinarios suplen sus veces, y éstos, como he dicho, se mudan todos los años; porque aunque en otros magistrados se suele poner en questión, si es mejor que duren por más tiempo, o que sean perpetuos, de que diré algo en otro lugar, en estos alcaldes que así ze nombran por los Cabildos, casi todas las naciones del mundo les dan sólo un año, porque este honor se reparta entre más ciudadanos, como consta de lo que después de Aristóteles dicen algunos textos de los del Derecho común y del Rey y varios autores. Y de muchas Cédulas Reales antiguas de las Indias que tratan de la elección y jurisdicción de estos alcaldes, del uso y forma de ella... Y entre otras cosas ordenan que se dejen en entera libertad a los Cabildos y Capitulares en la elección de ellos, prohibiendo extrechamente a los oidores de las Audiencias que por ningún modo se mezclen, metan ni interpongan en estas elecciones."

Esta cita de Solórzano Pereyra se refiere a los Municipios en su parte general a un momento histórico, con lo cual no quiere decir que en todas las circunstancias los cargos municipales se eligiesen así. El procedimiento siguió la misma evolución que en la Península; pero, a grandes rasgos, puede reducirse a tres tipos: cuando se fundaba una nueva población o se poblaba una existente, el primer Ayuntamiento era, generalmente, designado por el conquistador, Virrey, Capitán General, Audiencia, según los casos. Luego el Municipio sacaba de sí sus propios órganos directivos por régimen de elección y alternando con él, y sobre todo a medida que se imponía el centralismo, se iban cubriendo los cargos municipales por venta o designación superior o hereditaria. 


\section{Los Cabildos y la emancipación de América.}

Resumiendo, la organización municipal era tan perfecta en la América del Imperio, que al yanqui Brackenridge, hace bastante más de cien años, le parecía "excesivamente condescendiente". En reconocimiento de esto mismo, creo oportuno recordar estas palabras del erudito estadista y general argentino don Bartolomé Mitre, dichas en elogio de nuestras instituciones municipales de América en unos momentos en que muchos renegaban públicamente del nombre español: "La Municipalidad bajo el nombre de Cabildo, institución que la España nos había otorgado y que entrañaba un principio democrático y de libertad, debía dar, con el tiempo, el fruto que en la madre Patria no había podido madurar. La España tuvo, antes que en la Inglaterra, la inteligencia y la conciencia de las instituciones libres de propio Gobierno. Teníamos los Cabildos, y los Cabildos abiertos, es decir, la sombra de la Municipalidad y el medio de dar participaciones al pueblo en la cosa pública..." "La España, en verdad, concedía a la América todo lo que ella tenía y dió a sus colonos, por efecto de la lejanía tal vez: más libertad y más franquicias municipales que las que gozaban sus propios hijos en su territorio."

Años después, otro ilustre argentino, don Vicente G. Quesada, al estudiar el Municipio de la época imperial en su obra "La sociedad hispanoamericana bajo la dominación española", encuentra en lus Cabildos el origen de lo que él llama, influído por la revolución norteamericana, "self-government" (propio Gobierno) hispanoamericano.

Efectivamente, este es otro aspecto de la grandísima transcendencia histórica que le cupo al Municipio indiano: la de ser núcleo principal que façilitó la emancipación y la de dar carácter federal a la mayoría de los Estados que surgieron de las fracciones del Imperio. Quizás la evolución política de la Argentina en los cincuenta años que siguieron a la independencia sea, entre todos los ejemplos de la América española, el que más claramente nos acusa los fundamentos municipalistas de su federalismo.

En efecto, mientras el Virrey, los Capitanes generales, las Audiencias y otros organismos superiores eran designados directamenfe por la Corona y representaban los intereses de la gran unidad imperial, los Municipios tenían vida autónoma y se consagraban a los problemas pequeños de la comarca donde estaban asentados. Obra y sustancia, al principio, de los pobladores hispano-peninsulares, fueron herederos sus hijos, los hispanoamericanos, y al cabo de tres siglos representaban los intereses de éstos y la lejanía de la metrópoli. Por eso, cuando el ramalazo unánime promovido por la invasión napoléb- 
nica sacudió al mundo hispánico, fueron los Cabildos o Municipios americanos la base y el marco de aquellas Juntas, preludio de los Gobiernos independientes. Por ello bien puede decirse que, aunque sobre la demarcación territorial de las antiguas Audiencias, los nuevos Estados hispanos de América nacieron de los viejos Municipios que los soldados y los juristas de Castilla habían transplantado a las Indias.

\title{
Colofón.
}

En este breve boceto creo que queda perfilada, a grandes rasgos, la fisonomía y la importancia del Municipio español en las Indias. Sobre el tema hay algunos intentos, muy estimables; pero falta la obra completa y científica que se merece tan interesante institución. La historia jurídica del mundo hispánico la requiere. Elementos existen sobrados en los archivos de América y la Península, en el de Indiàs de Sevilla y en las recopilaciones y Cedularios del Derecho del antiguo régimen, incluso para ir estudiando Municipio por Municipio, y sólo falta el historiador y jurista que ponga con entusiasmo, decisión y competencia sus manos en la obra.

\author{
J. E. Casariego \\ Doctor en Derecho. \\ Consejero de la Hispanidad.
}

